\title{
Effects of Sterile Ulva sp. Growth Rate on Water Quality Control of Intensive Shrimp Culture Pond in Developing Countries
}

\author{
H. Habaki, ${ }^{a}$ Y. Aoki, ${ }^{a}$ R. Egashira,,${ }^{a, *}$ K. Sato, ${ }^{\text {b }}$ and T. Eksangsric \\ ${ }^{a}$ Department of Transdisciplinary Science and Engineering, \\ School of Environmental and Society, Tokyo Institute of Technology \\ ${ }^{b}$ Mitsubishi Gas Chemical Company, Inc. \\ 'Department of Chemical Engineering, Faculty of Engineering, \\ Thammasat University
}

doi: 10.15255/CABEQ.2014.2123

Original scientific paper

Received: October 1, 2014

Accepted: September 12, 2016

To control the water quality in the intensive shrimp mariculture pond by uptaking the total ammonia-nitrogen with sterile Ulva sp., the growth rate of sterile Ulva sp. was experimentally measured and the influence of the rate on the water quality control evaluated. The specific growth rate constant of the seaweed increased with the total ammonia-nitrogen concentration, photosynthetic photon flux density and operating temperature. Then the dynamics of ammonia-nitrogen in the modeled culture pond for the intensive shrimp farming in the tropical region were numerically simulated, in which the seaweed was used to uptake ammonia-nitrogen. The seaweed could uptake ammonia-nitrogen effectively during daytime mainly due to the high intensity of sun light, and the total ammonia-nitrogen concentration in the shrimp pond could be kept very low. The required seaweed density to control the total ammonia-nitrogen concentration less than the recommended maximum concentration of $1.0 \cdot 10^{-3} \mathrm{~kg} \mathrm{~N} \mathrm{~m}^{-3}$ was estimated to be reasonable.

Key words:

water quality control, intensive shrimp culture ponds, ammonia-nitrogen uptake, sterile Ulva sp.

\section{Introduction}

The mariculture industry has actively been developed due to the expanding demand for seafood worldwide. The shrimp culture was also industrialized especially in developing countries to bring a large profit. However, massive shrimp mortality caused by infectious diseases has been regarded as a serious issue for shrimp culture industries. The white spot syndrome virus is one of the most serious pathogens, and it has been causing frequent epidemics since the $1990 \mathrm{~s}^{1-3}$. Up to then, shrimp farming had been operated in the traditional system with water exchange and closed-intensive shrimp farming was suggested as one of the most promising systems to reduce the risk of virus contamination from the traditional system with water exchange ${ }^{2}$. Moreover, the closed culture pond system can reduce the waste solution which might cause damage to the water quality in the surrounding environment ${ }^{3}$.

The major issue related to the closed system is the rapid eutrophication in the culture pond. The components causing the eutrophication are inorganic and organic nitrogens, phosphate, and so on.

${ }^{*}$ Corresponding author. regashir@tse.ens.titech.ac.jp
Among these compounds, inorganic nitrogen, i.e. ammonia-nitrogen (ammonia-N), is the most toxic to cause growth inhibition of the shrimp, and mortality. The ammonia-N removal system is a key technology to control the quality of culture pond water for intensive shrimp farming.

Ryther et al. ${ }^{4}$ first suggested the application of a biofilter with seaweed to control water quality for the fish mariculture system. Ammonia-N could be removed by biofiltration with microalga, effectively converting from ammonia-N to nitrate less toxic for the aquafarming fishery products ${ }^{6-9}$. The biofilter systems employing macroalga have reported that $70-95 \%$ of ammonia-N in the effluent could be removed using Gracilaria chilensis in salmon aquaculture ponds ${ }^{10,11}$ and some research activities were reported on the application of Ulva lactuca to the farming of Oreochromis spilurus to control the water quality in the aquaculture ${ }^{12}$. On the other hand, different types of treatment systems have been suggested, in which the separation of ammonia-N by some kinds of adsorbents should be carried out to control the water quality of the culture pond. Activated carbon prepared from coconut shell was applied for the removal of the ammonia-N content from synthesized aqueous solution, and the fundamental performances of the adsorption were pre- 


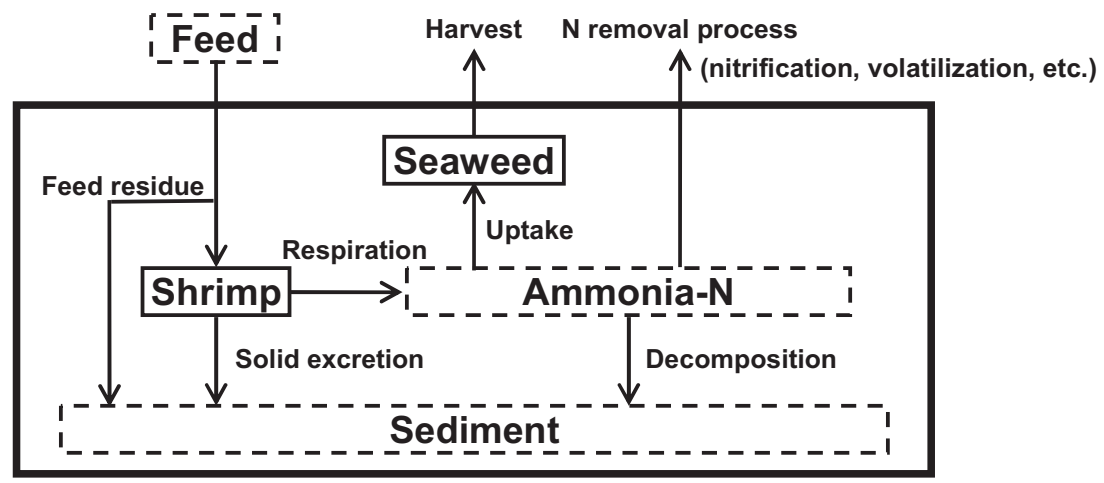

Fig. 1 - Schematic diagram of ammonia dynamics in shrimp pond

sented $^{13}$. Zeolite, which has an effective cation exchange capacity, was expected to effectively remove ammonium cation in the aqueous solution. Arthur et al. ${ }^{14}$ reported that, although zeolite had powerful potential to reduce ammonia-N content in the shrimp pond, it was found to be ineffective in sea water due to competitive ion-exchange with other cations. The application of natural zeolite was reported to study the effects of the salinity on the removal of ammonia-N content in the culture solution $^{15}$. Although biofilter systems with seaweed and separation systems with some adsorbents could stably control the water quality conditions for the fish and a final effluent low in waste products, the facilities would be rather complicated, and it is therefore necessary to develop a simpler system, especially in developing countries.

The authors tested sterile Ulva sp. to uptake ammonia-N, and nitrate-nitrogen ${ }^{16,17}$, and the control of the culture-pond water quality with this seaweed was suggested ${ }^{16-20}$. The seaweed would be cultivated in the culture pond together with shrimp for the water quality control. The uptake rate of ammonia-nitrogen followed the Michaelis-Menten model with uncompetitive inhibition. The uptake rate of ammonia-N increased with total ammonia-N concentration, photosynthetic photon flux density and temperature in the specified ranges. The growth of this seaweed needs to be considered for the design of this system, however the growth rate of this seaweed has yet to be studied.

This study aims to evaluate the potential of the water quality control in the intensive shrimp culture pond by sterile Ulva sp. with the consideration of the effects of the seaweed growth rate. The growth rates of the seaweed were measured experimentally in terms of the effects of ammonia- $\mathrm{N}$ concentration in the culture pond, photosynthetic photon flux density, and temperature. Then the ammonia-N uptake by the simple system using seaweed, which would be applied to the intensive shrimp culture pond in the developing countries, was simulated to evaluate the water quality control by the system.

\section{Nitrogen balance and growth of seaweed in the model shrimp pond}

Figure 1 shows the conceptual diagram of nitrogen dynamics around the model shrimp culture pond, developed in this study based on the works of Burford and Lorenzen ${ }^{21,22}$. Nitrogen is supplied into the model pond as the form of shrimp feed. Shrimp consumes much of the feed, and the uneaten feed is deposited as sediment in the pond. The solid excretion from the shrimp is also accumulated as sediment. There are two ways to generate ammonia-N: respiration of shrimp and sediment decomposition. Ammonia-N in the culture pond is removed only by seaweed uptake. Other processes of ammonia-N removal, such as nitrification, volatilization, assimilation by other plants, water exchange, and so on, are neglected. The material balance of ammonia- $\mathrm{N}$ in a unit volume of shrimp pond is given by,

$$
\frac{\mathrm{d} C_{\text {TAN }}}{\mathrm{d} t}=r_{\text {total,TAN }}-r_{\text {total,remove }}
$$

where $C_{\mathrm{TAN}}, r_{\text {total,TAN }}$ and $r_{\text {total, remove }}$ are the concentration of total ammonia- $\mathrm{N}$ in the culture pond, and rates of generation and removal of ammona-N, respectively.

\section{Ammonia-N generation}

Ammonia-N generation, produced from the respiration of shrimp and decomposition of the sediment, is given as:

$$
r_{\text {Total,TAN }}=r_{\mathrm{Shr}, \mathrm{TAN}}+r_{\mathrm{Sed}, \mathrm{TAN}}
$$

where $r_{\text {Shr,TAN }}$ and $r_{\text {Sed,TAN }}$ are the generation rates of ammonia-N from the respiration of shrimp and decomposition of sediment, respectively. The $r_{\mathrm{Shr}, \mathrm{TAN}}$ is given by,

$$
r_{\mathrm{Shr}, \mathrm{TAN}}=\rho_{\mathrm{TAN}} r_{\mathrm{mbt}, \mathrm{N}}
$$

where $\rho_{\text {TAN }}$ is the fraction of ammonia-N generated from the respiration of shrimp to the total nitrogen metabolite by shrimp. The $r_{\mathrm{mtb}, \mathrm{N}}$ is the excretion rate 
of total nitrogen due to shrimp metabolite per unit volume of shrimp pond, given by,

$$
r_{\mathrm{mb}, \mathrm{N}}=a_{\mathrm{mbl}, \mathrm{N}} \rho_{\mathrm{S}} M_{\mathrm{S}}^{\gamma}
$$

where $a_{\mathrm{mtb}, \mathrm{N}}$ is the generation rate of nitrogen due to shrimp metabolite per unit shrimp mass, $\rho_{\mathrm{S}}$ is the culture density of shrimp, $M_{\mathrm{S}}$ is average shrimp mass and estimated from the growth model, $\gamma$ is an allometric scaling parameter of shrimp metabolism. The average mass of shrimp was estimated based on the growth model as the von Bertalaffy Growth Function $^{23}$,

$$
M_{\mathrm{S}}=\left\{M_{\mathrm{S}, \max }^{1 / 3}-\left(M_{\mathrm{S}, \max }^{1 / 3}-M_{\mathrm{S}, 0}^{1 / 3}\right) \exp ^{-K_{\mathrm{g}} \cdot t}\right\}^{3}
$$

where $M_{\mathrm{S}, \max }, M_{\mathrm{S}, 0}$, and $K_{\mathrm{g}}$ are the asymptotic weight of shrimp, weight at the initial condition, and growth coefficient of shrimp, respectively. The density of shrimp in the culture pond is given by an exponential mortality model ${ }^{21}$, expressed as,

$$
\rho_{\mathrm{S}}=\rho_{\mathrm{S}, 0} \exp \left(-K_{\mathrm{m}} t\right)
$$

where $\rho_{\mathrm{S}, 0}$ and $K_{\mathrm{m}}$ are the density of shrimp at the initial condition and natural mortality rate constant. The accumulation rate of nitrogen in the sediment is expressed as,

$$
\frac{\mathrm{d} M_{\mathrm{Sed}, \mathrm{N}}}{\mathrm{d} t}=q_{\mathrm{N}} r_{\mathrm{F}} R_{\mathrm{Sed}}+r_{\mathrm{mtb}, \mathrm{N}}\left(1-q_{\mathrm{TAN}}\right)-r_{\mathrm{Sed}, \mathrm{TAN}}
$$

where $M_{\mathrm{SedN}}$ is the amount of nitrogen contained in the sediment per unit volume of shrimp pond. The three terms on the right side are the accumulation rate of nitrogen from uneaten feed, discharge rate of nitrogen from shrimp excretion except for respiration, and decomposition rate of the sediment, respectively, where $q_{\mathrm{N}}, r_{\mathrm{F}}, R_{\mathrm{Sed}}$, and $r_{\text {SedTAN }}$ are the mass fraction of nitrogen in the feed, feeding rate, ratio of uneaten feed to the total feed, and generation rate of ammonia-N from decomposition of sediment, respectively. The decomposition of the sediment was estimated with the assumption that the decomposition rate should follow the first order reaction $^{21}$, and the generation rate of ammonia-N due to the decomposition of sediment, $r_{\text {Sed,TAN }}$, is given by,

$$
r_{\text {Sed,TAN }}=r_{\mathrm{r}} M_{\mathrm{Sed}, \mathrm{N}}
$$

where $r_{\mathrm{r}}$ is the rate constant of decomposition.

\section{Ammonia-N removal}

The removal rate of ammonium-N in a unit volume of shrimp pond is given by,

$$
r_{\text {total,remove }}=\rho_{\mathrm{U}} \pi_{\mathrm{TAN}}
$$

where $\rho_{\mathrm{U}}$ and $\pi_{\mathrm{TAN}}$ are the density of seaweed in shrimp pond and specific uptake rate of ammonia-N by seaweed. The growth of sterile Ulva sp. was as- sumed to follow the model of the autocatalytic reaction, and the growth is expressed as,

$$
\frac{\mathrm{d} \rho_{\mathrm{U}}}{\mathrm{d} t}=\mu \rho_{\mathrm{U}}, \quad \ln \frac{\rho_{\mathrm{U}}}{\rho_{\mathrm{U}, 0}}=\mu t
$$

where $\mu$ is the specific growth rate constant. It was reported that this constant should be affected by some factors, and $\mu$ was expressed as a function of $C_{\text {TAN }}$, photosynthetic photon flux density, $I$, and temperature, $T$, and in this study it was assumed that $\mu$ could be expressed as,

$$
\mu=\mu_{\text {max }} \frac{C_{\mathrm{TAN}}}{K_{\mathrm{S}}+C_{\mathrm{TAN}}} \frac{I}{I_{\mathrm{S}}+I} \exp \left(-\frac{E}{R T}\right)
$$

where $K_{\mathrm{s}}, I_{\mathrm{s}}$, and $E$ mean the half saturation constants for $C_{\mathrm{TAN}}^{\mathrm{s}}$ and $I$, and apparent activation energy for ammonia-N uptake, respectively. The effects of $C_{\text {TAN }}, I$ and $T$ on $\mu$ were considered to follow the Monod model, model suggested by Ogawa et al. ${ }^{24}$, and the Arrhenius model, respectively. The uptake rate of ammonia-N by the seaweed, $\pi_{\mathrm{TAN}}$, and the Michaelis-Menten model are given by the following equations, such as,

$\pi_{\mathrm{TAN}}=-\frac{1}{\rho_{\mathrm{U}}} \frac{\mathrm{d} C_{\mathrm{TAN}}}{\mathrm{d} t}, \quad \pi_{\mathrm{TAN}}=\frac{\pi_{\mathrm{max}} \cdot C_{\mathrm{TAN}}}{K_{\mathrm{M}}+C_{\mathrm{TAN}}}(13)$,

where $\pi_{\max }$ and $K_{\mathrm{M}}$ are the maximum specific uptake rate, and half saturation constant of TAN concentration, respectively. Considering that the uptake of ammonia- $\mathrm{N}$ is necessary for seaweed growth, the uptake rate of ammonia-N by the seaweed, $\pi_{\mathrm{TAN}}$, is closely related to the growth rate of the seaweed. Then $\pi_{\text {TAN }}$ was assumed able to be derived in the similar way as $\mu$. The effects of $C_{\text {TAN }}$ on $\pi_{\text {TAN }}$ were represented by the Michaelis-Menten model, and the effects of $I$ and $T$ were assumed to follow the model suggested by Ogawa et al. ${ }^{24}$ and the Arrhenius model, respectively. Then Eq. (14) was rewritten as,

$$
\pi_{\mathrm{TAN}}=\pi_{\text {max }}^{\prime} \frac{C_{\mathrm{TAN}}}{K_{\mathrm{M}}+C_{\mathrm{TAN}}} \frac{I}{I_{\mathrm{S}}+I} \exp \left(-\frac{E}{R T}\right)
$$

The parameters of $\mu_{\max }, K_{\mathrm{M}}, K_{\mathrm{s}}, I_{\mathrm{s}}$, and $E$ would experimentally be obtained in the following discussion, and the value of $\pi_{\text {max }}^{\prime}$ was estimated later with the assumption that $\mu$ was proportional to $\pi_{\mathrm{TAN}}$.

\section{Effects of operating conditions on ammonia-nitrogen uptake by sterile seaweed}

\section{Experimental study of ammonia-nitrogen uptake and growth rate of sterile seaweed}

\section{Materials}

Sterile Ulva sp. was collected from March to August 2011 from Kanazawa Bay, in Yokohama, 
Japan $35^{\circ} 20^{\prime} 32 \mathrm{~N}, 139^{\circ} 38^{\prime} 32 \mathrm{E}$, and the principal characteristics of the seaweed used in this study were shown in our previous studies. Commercial sea salt of Aqua Zalts, purchased from Nissei Sangyo Co. Ltd., was used to prepare artificial seawater whose salinity was set as $30 \%$. Ammonium chloride, sodium dihydrogen phosphate and sodium hydrogen carbonate, which were special grade from Wako Pure Chemical Industries, Ltd., were used as sources of ammonia-N, dissolved inorganic phosphorus, and dissolved inorganic carbon in the seawater.

\section{Preservation of seaweed}

The collected seaweed was preserved using the same method as described in our previous works. ${ }^{23}$ The principal conditions for the preservation are shown in Table 1. A commercially available glass beaker of $5.0 \cdot 10^{-4} \mathrm{~m}^{3}$ was used as an aquarium, equipped with aeration agitation and metal halide lamp, EYE Clean-Ace M400DL/BUDP, purchased from Iwasaki Electric Co., Ltd. (Japan). The collected seaweed was meticulously washed with artificial seawater to remove epiphytes and mud, and cultivated in the apparatus for more than 24 hours with the artificial seawater containing no additive agent, to prepare "starved seaweed". The temperature and photosynthetic photon flux density, $I$, were controlled at $295 \mathrm{~K}$ and $800 \mu \mathrm{mol} \mathrm{m} \mathrm{s}^{-1}$ as daytime conditions, and at $295 \mathrm{~K}$ and $0 \mu \mathrm{mol} \mathrm{m} \mathrm{m}^{-2} \mathrm{~s}^{-1}$ as nighttime conditions, respectively. The daytime/ nighttime cycle was fixed as 14 hours and 10 hours, respectively. After preservation, the dry mass of the seaweed, DM, was measured using the same method as in our previous work" ${ }^{11-13}$. The "starved seaweed" was wiped with paper towels to remove solution on the surface, and kept in the desiccator with silica gel at room temperature for several days until the mass of dried seaweed became constant, to be determined as the initial dry mass of the seaweed.

Table 1 - Principal experimental conditions for ammonia-nitrogen uptake by sterile Ulva sp.

\begin{tabular}{|c|c|c|}
\hline Total volume of aquarium, $V$ & {$\left[\mathrm{~m}^{-3}\right]$} & 0.0005 \\
\hline $\begin{array}{l}\text { Initial concentration of } \\
\text { ammonia-N in solution, } C_{\mathrm{TAN}, 0}\end{array}$ & {$\left[\mathrm{~kg} \mathrm{~N} \mathrm{~m}^{-3}\right]$} & $0-0.005$ \\
\hline $\begin{array}{l}\text { Initial concentration of } \\
\text { phosphorous in solution, } C_{\mathrm{P}, 0}\end{array}$ & {$\left[\mathrm{~kg} \mathrm{P} \mathrm{m}^{-3}\right]$} & 0.0003 \\
\hline $\begin{array}{l}\text { Initial concentration of inorganic } \\
\text { carbon in solution, } C_{\mathrm{C}, 0}\end{array}$ & {$\left[\mathrm{~kg} \mathrm{C} \mathrm{m}^{-3}\right]$} & 0.024 \\
\hline Salinity of culture solution & {$\left[\mathrm{kg} \mathrm{m}^{-3}\right]$} & 30 \\
\hline Initial density of seaweed, $\rho_{\mathrm{U}, 0}$ & {$\left[\mathrm{~kg} \mathrm{DM} \mathrm{m}^{-3}\right]$} & $0.15 \pm 0.03$ \\
\hline $\begin{array}{l}\text { Photosynthetic photon flux } \\
\text { density, } I\end{array}$ & {$\left[\mu \mathrm{mol} \mathrm{s}{ }^{-1} \mathrm{~m}^{-2}\right]$} & $0-2000$ \\
\hline Temperature, $T$ & {$[\mathrm{~K}]$} & $287-313$ \\
\hline
\end{tabular}

Temp. controller

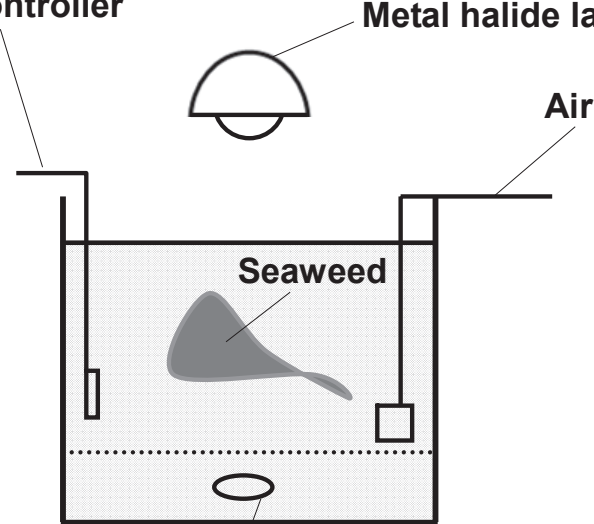

Magnetic stirrer

Fig. 2 - Schematic diagram of experimental apparatus for batch uptake measurements

Uptake of ammonia-N by seaweed

The principal conditions and experimental apparatus for ammonia- $\mathrm{N}$ uptake by seaweed are shown in Table 2 and Fig. 2, respectively. A metal halide lamp was used as a light source, and $I$ was measured at several points of the solution surface by a quantum meter, same as in the preservation. A magnetic stirring tip was used to completely mix the culture solution. To avoid the seaweed from being torn apart by contact with the stirrer tip, a nylon net of $3360 \mu \mathrm{m}$ line gap and $1000 \mu \mathrm{m}$ diameter line was equipped to cover the agitation part by the magnetic stirrer. The seaweed could not pass through the net and the solution in the vessel could be fully agitated. Before each uptake run, the starved seaweed was acclimatized for more than 0.5 $\mathrm{h}$ at $295 \mathrm{~K}$ and $800 \mu \mathrm{mol} \mathrm{m} \mathrm{m}^{-2}$ in the culture solution without ammonia-N. The specified amounts of ammonia-N, dissolved inorganic phosphorus, and dissolved inorganic carbon were added to the cultivation solution to start the uptake run. After the specified periods of the ammonia-N uptake, the concentration of total ammonia- $\mathrm{N}$ in the solution, $C_{\mathrm{TAN}}$, and DM were measured. The $C_{\mathrm{TAN}, 0}, I$, and $T$ were varied to study the effects on the seaweed growth rate.

Analysis

The concentration of ammonia- $\mathrm{N}$ in the solution was determined by the indophenol blue method. The $I$ was measured at several points of the solution surface by a quantum meter of Model QMSS of Apogee Instruments Inc.

\section{Numerical simulation of culture-pond quality control by sterile seaweed}

The control of water quality in the model culture pond was simulated in terms of the dynamics 
Table 2 - Principal experimental conditions for ammonia-nitrogen uptake by sterile Ulva sp.

Parameters relating to ammonia- $\mathrm{N}$ generation

\begin{tabular}{|c|c|c|}
\hline $\begin{array}{l}\text { Fraction of ammonia-N due to } \\
\text { shrimp respiration, } \rho_{\text {TAN }}\end{array}$ & {$[-]$} & 0.8 \\
\hline $\begin{array}{l}\text { Allometric scaling parameter of } \\
\text { shrimp metabolism, } \gamma\end{array}$ & {$[-]$} & 0.75 \\
\hline Maxmum weight of shrimp, $M_{\mathrm{S}, \max }$ & [kg shrimp] & 0.13 \\
\hline Growth coefficient of shrimp, $K_{\mathrm{g}}$ & {$\left[\mathrm{h}^{-1}\right]$} & 0.00031 \\
\hline Natural mortality rate constant, $K_{\mathrm{m}}$ & {$\left[\mathrm{h}^{-1}\right]$} & 0.000078 \\
\hline Mass fraction of nitrogen in feed, $\rho_{\mathrm{N}}$ & {$[-]$} & 0.046 \\
\hline $\begin{array}{l}\text { Ratio of uneaten feed to total } \\
\text { feed, } R_{\text {Sed }}\end{array}$ & {$[-]$} & 0.1 \\
\hline $\begin{array}{l}\text { Rate constant sediment } \\
\text { decomposition, } r_{\mathrm{r}}\end{array}$ & {$\left[\mathrm{h}^{-1}\right]$} & 0.0025 \\
\hline
\end{tabular}

\begin{tabular}{|c|c|c|}
\hline \multicolumn{3}{|c|}{ Parameters relating to ammonia-N uptake } \\
\hline Half saturation constant for $C_{\mathrm{TAN}}$ & {$\left[\mathrm{kg} \mathrm{m}^{-3}\right]$} & 0.0018 \\
\hline Half saturation constant for $C_{\mathrm{TAN}}$ & {$\left[\mathrm{kg} \mathrm{m}^{-3}\right]$} & 0.0023 \\
\hline Half saturation constant for $I, I_{\mathrm{S}}$ & {$\left[\mu \mathrm{mol} \mathrm{s}^{-1} \mathrm{~m}^{-2}\right]$} & 190 \\
\hline \multirow[t]{2}{*}{ Maximum $I, I_{\max }$} & {$\left[\mu \mathrm{mol} \mathrm{s}^{-1} \mathrm{~m}^{-2}\right]$} & $\begin{array}{l}\text { 1800: } \\
\text { clear day }\end{array}$ \\
\hline & & $\begin{array}{l}100: \\
\text { cloudy/ } \\
\text { rainy day }\end{array}$ \\
\hline Maximum $T, I_{\max }$ & {$[\mathrm{K}]$} & 303 \\
\hline Minimum $T, I_{\min }$ & {$[\mathrm{K}]$} & 298 \\
\hline Apparent activation energy, $E$ & {$\left[\mathrm{~J} \mathrm{~mol}^{-1}\right]$} & 69000 \\
\hline \multicolumn{3}{|c|}{ Initial conditions } \\
\hline $\begin{array}{l}\text { Initial ammonia- } \mathrm{N} \text { concentration } \\
\text { in culture pond, } C_{\mathrm{TAN}, 0}\end{array}$ & {$\left[\mathrm{~kg} \mathrm{~N} \mathrm{~m}^{-3}\right]$} & 0 \\
\hline Initial weight of shrimp, $M_{\mathrm{S}, 0}$ & [kg shrimp] & 0.0001 \\
\hline Initial density of seaweed, $\rho_{\mathrm{U}, 0}$ & {$\left[\mathrm{~kg} \mathrm{DM} \mathrm{m} \mathrm{D}^{-3}\right]$} & 1.0 \\
\hline Initial density of shrimp, $\rho_{\mathrm{S}, 0}$ & {$\left[\mathrm{~m}^{-3}\right]$} & 40 \\
\hline
\end{tabular}

Table 3 -Feeding schedule for shrimp

\begin{tabular}{cc}
\hline Shrimp mass, $M_{\mathrm{S}}[\mathrm{kg}]$ & $\begin{array}{r}\text { Feeding rate, } r_{\mathrm{F}} \\
{\left[\mathrm{kg} \text { feed } \mathrm{kg}^{-1} \text { shrimp } \mathrm{h}^{-1}\right]}\end{array}$ \\
\hline 0.0002 and below 0.0057 & 0.005 \\
$0.002-0.013$ & 0.0017 \\
$0.013-0.03$ & \\
0.03 and above 0.0012 & \\
\hline
\end{tabular}

of ammonia-N, as illustrated in Fig. 1. The values of the coefficients relating to the ammonia- $\mathrm{N}$ generation and uptake of ammonia-N by the seaweed, and calculation conditions are listed in Table 2. Penaeus monodon was selected as the model shrimp because it was the most popular shrimp for farming in Southeast Asian countries. For the parameters relating to the growth of Penaeus monodon, $\gamma$ of Eq. (4), and $M_{\mathrm{S}, 0}, M_{\mathrm{S}, \max }, K_{\mathrm{g}}$ of Eq. (5) were referred to the previous studies ${ }^{14,10}$. The feeding rate was decided according to the work of Lim, and is listed in Table $3 .{ }^{26}$ The parameters relating to the properties of the sediment and its decomposition, such as $R_{\mathrm{Sed}}$, $r_{\mathrm{r}} q_{\mathrm{N}}$, were also referred to the previous studies ${ }^{25,21}$.

The climate conditions were determined based on the report from Thai Meteorological Department and research of pond water temperature change in Rayong of Thailand ${ }^{27,28}$. The times of sunrise and sunset are approximately 6:00 a.m. and 6:00 p.m. throughout the year, and the time at the culmination point of the sun is nearly at noon. Then, the $I$ and $T$ are expressed as,

$I=I_{\max } \sin ^{2}\left\{\frac{\pi(t-6)}{12}\right\}(6 \mathrm{~h} \leq t<18 \mathrm{~h}$ : daytime $)$

$I=0(0 \mathrm{~h} \leq t<6 \mathrm{~h}, 18 \mathrm{~h} \leq t<24 \mathrm{~h}$ : nighttime $)(17)$

$T=T_{\min }+\left(T_{\max }-T_{\min }\right) \cdot \sin \left(\frac{t-L S H+D L / 2}{D L+2 P} \pi\right)$

$(6 \mathrm{~h} \leq t<18 \mathrm{~h}$ : daytime $)$

$T=\frac{T_{\min }-T_{\mathrm{s}} \cdot \exp (-\eta / \tau)+\left(T_{\mathrm{s}}-T_{\min }\right) \cdot \exp \left\{-\left(t-t_{\mathrm{s}}\right) / \tau\right\}}{1-\exp (-\eta / \tau)}$

$(0 \mathrm{~h} \leq t<6 \mathrm{~h}, 18 \mathrm{~h} \leq t<24 \mathrm{~h}$ : nighttime $)$

where $I_{\max }$ is the photosynthetic photon flux density at the culmination point of the sun, and fixed as $1800 \mu \mathrm{mol} \mathrm{m} \mathrm{m}^{-2}$ in clear days and $100 \mu \mathrm{mol} \mathrm{m} \mathrm{m}^{-2} \mathrm{~s}^{-1}$ in cloudy or rainy days; $T_{\max }$ and $T_{\min }$ are the maximum and minimum temperatures fixed as $303 \mathrm{~K}$ and $298 \mathrm{~K}$, attained two hours after the culmination point of the sun and just before sunrise, respectively; $L S H, D L, T_{\mathrm{s}}, t_{\mathrm{s}}, \tau$, and $\eta$ are the time at the culmination point of the sun, daylight hours, sunset temperature, sunset time, time coefficient, and nighttime length; $C_{\mathrm{TAN}, 0}$ and $M_{\mathrm{Sed}, \mathrm{N}, 0}$ were decided as $0 \mathrm{~kg} \mathrm{~N} \mathrm{~m}^{-3}$ for both, and $\rho_{\mathrm{U}, 0}$ was set as $1.0 \mathrm{~kg} \mathrm{DM} \mathrm{m}^{-3}$. For the evaluation of water quality control in the intensive culture pond, the culture density of shrimp, $\rho_{\mathrm{S}, 0}$ was $40 \mathrm{~m}^{-3}$. Pond area and depth were $4000 \mathrm{~m}^{2}$ and $1.0 \mathrm{~m}$. The cultivation period was decided for 90 days, which was a general period for cultivation of the shrimp. With these conditions and equations, the dynamics of ammonia-N around the model culture pond was simulated. 


\section{Results and discussion}

\section{Experimental study of ammonia-nitrogen uptake and growth rate of sterile seaweed}

Figure 3 shows the Michaelis-Menten plot for the ammonia-N uptake with the seaweed at $T=300$ $\mathrm{K}$. The uptake rate of ammonia-N increased as $C_{\text {TAN, }, 0}$, and asymptotically attained constant value in the range of higher $C_{\mathrm{TAN}, 0}$, as observed in the previous study. Then, the $K_{\mathrm{M}}$ and $\pi_{\text {max }}$ in Eq. (14) were estimated as $2.3 \cdot 10^{-3} \mathrm{~kg} \mathrm{~N} \mathrm{~m}^{-3}$ and $11.6 \cdot 10^{-3}$ $\mathrm{kg} \mathrm{N} \mathrm{kg} \mathrm{DM}{ }^{-1} \mathrm{~h}^{-1}$, respectively. Although the $K_{\mathrm{M}}$ value in this study was slightly smaller than that in the previous study $\left(K_{\mathrm{M}}=8.1 \cdot 10^{-3} \mathrm{~kg} \mathrm{~N} \mathrm{~m}^{-3}\right)$, the $\pi_{\max }$ value was same as in the previous study $\left(\pi_{\max }=11.3 \cdot 10^{-3} \mathrm{~kg} \mathrm{~N} \mathrm{~kg} \mathrm{DM}^{-1} \mathrm{~h}^{-1}\right)$. The seaweed used in this study was regarded to show approximately the same performance for the ammonia- $\mathrm{N}$ uptake as the seaweed used in the previous study.

Figure 4 shows the effects of $C_{\mathrm{TAN}}, I$ and $T$ on $\rho_{\mathrm{U}} / \rho_{\mathrm{U}, 0}$. The $\rho_{\mathrm{U}} / \rho_{\mathrm{U}, 0}$ increased as did the uptake time, $t$, and with an increase in these three parameters. When $C_{\mathrm{TAN}}=0$ and $I=0, \rho_{\mathrm{U}} / \rho_{\mathrm{U}, 0}$ remained unchanged to be kept at unity along the operating time. The logarithm of $\rho_{\mathrm{U}} / \rho_{\mathrm{U}, 0}$ was proportional to $t$ and it was confirmed that the seaweed growth followed the model of the autocatalytic reaction in this measurement range, as expressed by Eq. (11). When $C_{\text {TAN }}>40 \cdot 10^{-3} \mathrm{~kg} \mathrm{~N} \mathrm{~m}^{-3}$ or $T>308 \mathrm{~K}$, chlorosis of the seaweed was observed. This concentration range of TAN was much higher than the maximum TAN concentration recommended for stable farming of shrimp, $1.0 \cdot 10^{-3} \mathrm{~kg} \mathrm{~N} \mathrm{~m}^{-3}$. Even in tropical conditions, $T$ cannot be maintained more than $308 \mathrm{~K}$ for a long time. Therefore, the effects of chlorosis might be less serious in actual situations. In the range of $I>1500 \mu \mathrm{mol} \mathrm{m}{ }^{-2} \mathrm{~s}^{-1}, I$ had less influence on $\rho_{\mathrm{U}} / \rho_{\mathrm{U}, 0}$ and almost kept constant. Figure 5 shows the effects of $C_{\mathrm{TAN}}, I$ and $T$ on $\mu$. In all cases, $\mu$ increased with $C_{\mathrm{TAN}}, I$, and $T$. With these results and

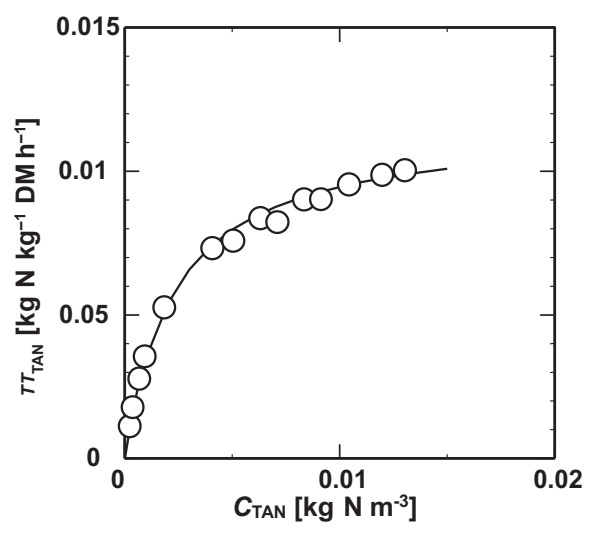

Fig. 3 - Michaelis-Menten plot
Eq. (3), the values of the four parameters were obtained as $\mu_{\max }=5.7 \cdot 10^{-1} \mathrm{~h}^{-1}, K_{\mathrm{S}}=1.8 \cdot 10^{-3} \mathrm{~kg} \mathrm{~N} \mathrm{~m}^{-3}$, $I_{\mathrm{S}}=189 \mu \mathrm{mol} \mathrm{m} \mathrm{s}^{-1}$ and $E=6.86 \cdot 10^{4} \mathrm{~J} \mathrm{~mol}^{-1}$. In this estimation, the results in which the chlorosis of seaweed was observed were excluded. Then, $\mu$ was estimated, and is shown by solid lines in Figure 3. The model of seaweed growth could fully express the growth of sterile Ulva sp. The average ratio of $\mu_{\max } / \pi_{\text {max }}$ was estimated at $2.1 \mathrm{~kg} \mathrm{DM} \mathrm{kg}^{-1} \mathrm{~N}$, used in the numerical simulation of shrimp culture pond quality.
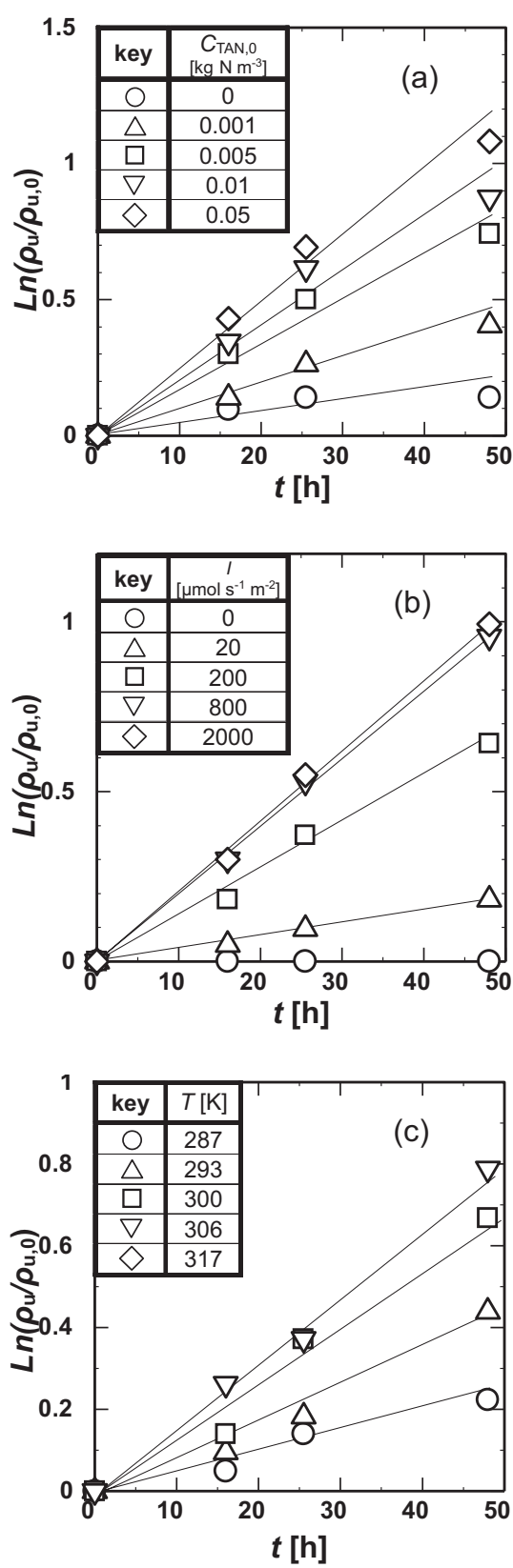

Fig. 4-Effects of initial concentration of total ammonia, $C_{T A N, 0^{\prime}}$ on ratio of seaweed density to initial seaweed density, $\rho_{u} / \rho_{u, 0}$ (a) effects of $C_{T A N, 0}$ on $\rho_{u} / \rho_{u, 0^{\prime}}$ (b) effects of I on $\rho_{u} / \rho_{u, 0}$, (c) effects of $T$ on $\rho_{u} / \rho_{u, 0}$ 

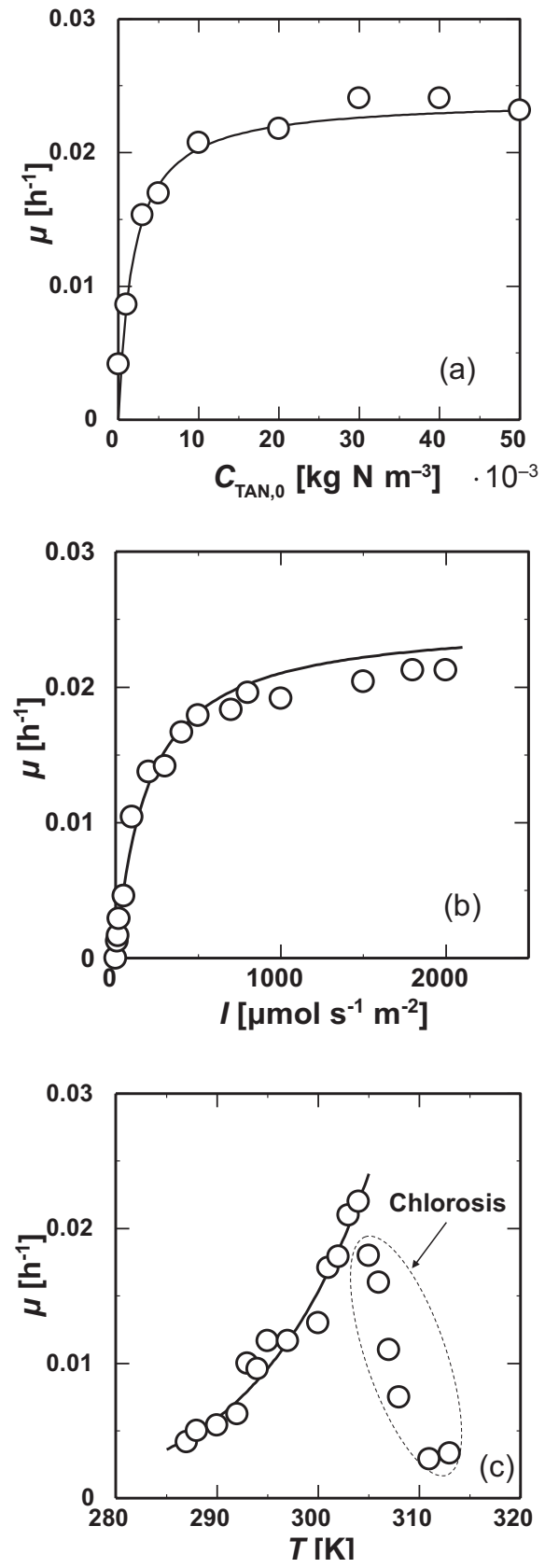

Fig. 5 - Effects of initial concentration of total ammonia, $C_{T, 0}$ on specific growth rate constant, $\mu$

(a) effects of $C_{T A N, 0}$ on $\rho_{u} / \rho_{u, 0}$, (b) effects of I on $\rho_{u} / \rho_{u, 0}$ (c) effects of $T$ on $\rho_{u} / \rho_{u, 0}$

\section{Numerical simulation of shrimp culture pond quality}

In this study, $C_{\mathrm{TAN}}, I$, and $T$ were assumed to influence the uptake rate of ammonia-N and seaweed growth rates in the same way, as shown in Eqs. (12) and (15), and $\pi_{\text {max }}$ was estimated from $\mu_{\max }$ and Eq. (15) at $1.2 \mathrm{~kg} \mathrm{~N} \mathrm{~kg}^{-1} \mathrm{DM} \mathrm{h}^{-1}$. Figure 6 shows the example of the time variations of $C_{\mathrm{TAN}}$ and removal rate of ammonia- $\mathrm{N}, r_{\text {totalremoval }}$, through the day on the 60th cultivation day. The $C_{\text {TAN }}$ de-

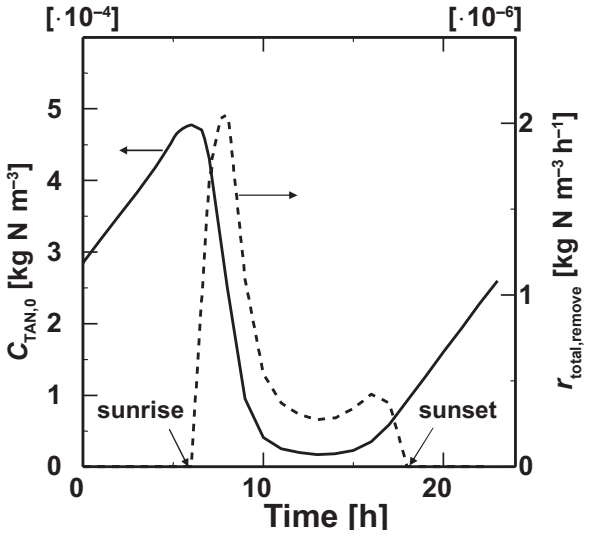

Fig. 6 - Time variations of $C_{\text {TAN }}$ and $r_{\text {total,removal }}$ on 60th cultivation day

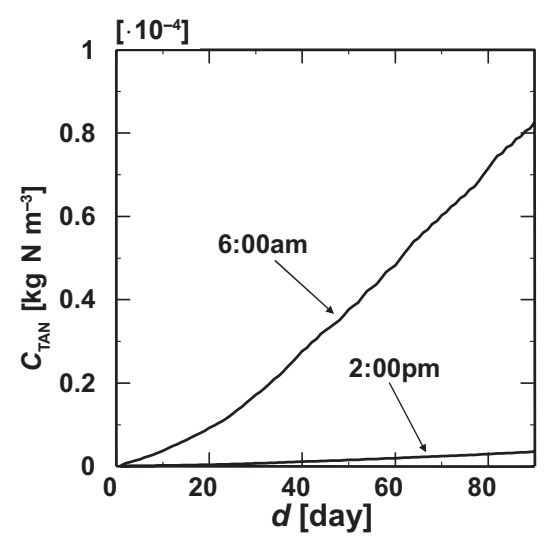

Fig. 7 - Transitions of $C_{\text {TAN }}$ s at 6:00 a.m. and 12:00 p.m. along cultivation period

creased from sunrise, attained minimum value around 2:00 p.m., and increased up to sunrise. After 2:00 p.m., $C_{\mathrm{TAN}}$ gradually increased with time, and the increment was accelerated after sunset. As expressed by Eq. (15), the seaweed was assumed to uptake no ammonia-N during the nighttime because $I=0$, i.e. $r_{\text {total remove }}=0$. Then the ammonia-N was accumulated during nighttime and the removal of ammonia-N started from sunrise. The $r_{\text {total remove }}$ suddenly increased from sunrise and attained maximum value around 9:00 a.m. In the morning, $C_{\mathrm{TAN}}$ was relatively high to cause large $r_{\text {total remove }}$. In the afternoon, $I$ and $T$ were relatively high, however $r_{\text {tow }}$ was small due to small $C_{\text {TA. }}$. Figure 7 shows the changes of $C_{\mathrm{TAN}} \mathrm{s}$ at 6:00 a.m. and 12:00 p.m. The seaweed could effectively control $C_{\text {TAN }}$ such low level around 12:00 p.m. During nighttime, the seaweed inefficiently took in ammonia- $\mathrm{N}$, and $C_{\mathrm{TAN}}$ became relatively high until 6:00 a.m. The recommended maximum $C_{\text {TAN }}$ was reported to be less than $1.0 \cdot 10^{-3} \mathrm{~kg} \mathrm{~N} \mathrm{~m}^{-3} .{ }^{\text {TAN }}$ The $C_{\mathrm{TAN}}$ could be controlled less than the recommended concentration of ammonia- $\mathrm{N}$ using the seaweed throughout the farming process. The $\rho_{\mathrm{U}}$ increased from $1.00 \mathrm{~kg} \mathrm{DM} \mathrm{m}^{-3}$ to 
$1.12 \mathrm{~kg} \mathrm{DM} \mathrm{m}^{-3}$ in 90 days. Then, $480 \mathrm{~kg}$ DM seaweed could be obtained as by-product when the general scale of the culture pond was used in which the area of the culture pond and depth were $4000 \mathrm{~m}^{2}$ and $1.0 \mathrm{~m}$, respectively. The shrimp pond is generally operated in a large area. Though the amount of harvested seaweed was relatively large, the increment of the seaweed density in the shrimp pond was insignificant. Therefore, the frequency of seaweed harvesting may be low, and operation is expected to be simple.

\section{Conclusions}

The growth rate of the sterile seaweed was measured to study the effect of the following operating conditions, such as the total ammonia-nitrogen concentration, photosynthetic photon flux density, and temperature. The seaweed density increased as these parameters increased. The logarithm of the seaweed density ratio was proportional to the operating time, and the growth was found to follow the model of the autocatalytic reaction in this measurement range. The specific growth rate constant increased as each parameter increased, and was represented by the Monod and Arrhenius models.

The water quality control using the sterile seaweed was numerically simulated, and the ammonia-nitrogen in the shrimp pond was effectively controlled with the seaweed. During daytime, the seaweed could effectively uptake ammonia-nitrogen to keep so low a level in the pond. On the other hand, during nighttime, the ammonia-nitrogen concentration should increase until daybreak because the seaweed should require sunlight to uptake ammonia-nitrogen. However, the maximum concentration was smaller than the permissible concentration and, consequently, this system could control the water quality in terms of ammonia-nitrogen concentration. After farming, a large amount of seaweed was obtained as by-product. The increment of the seaweed density was estimated to be small. This system required less frequency of seaweed harvesting and simple operation could be expected.

\footnotetext{
Nomenclature

$a_{\mathrm{mtb}, \mathrm{N}}-$ nitrogen metabolite excretion rate, $\mathrm{kg} \mathrm{N} \mathrm{kg}^{-1}$ shrimp $\mathrm{h}^{-1}$

$C_{\text {DIC }} \quad-$ inorganic carbon concentration, $\mathrm{kg} \mathrm{C} \mathrm{m}^{-3}$

$C_{\mathrm{DIP}} \quad-$ phosphorous concentration, $\mathrm{kg} \mathrm{P} \mathrm{m}^{-3}$

$C_{\text {TAN }}-$ TAN concentration, $\mathrm{kg} \mathrm{N} \mathrm{m}^{-3}$

d - cultivation time, day

$D L \quad$ - day length, h

E $\quad-$ apparent activation energy in Eq. (12), $\mathrm{J} \mathrm{mol}^{-1}$
}

$I$

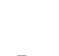

$I_{\max }$

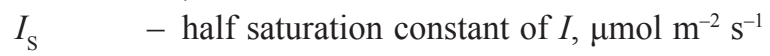

$K_{\mathrm{g}} \quad-$ growth coefficient of shrimp, $\mathrm{h}^{-1}$

$K_{\mathrm{M}} \quad-$ half saturation constant of TAN concentration for uptake, $\mathrm{kg} \mathrm{N} \mathrm{m}^{-3}$

$K_{\mathrm{S}} \quad-$ half saturation constant of TAN concentration for growth, $\mathrm{kg} \mathrm{N} \mathrm{m}^{-3}$

LSH - time of maximum solar height, $\mathrm{h}$

$M_{\mathrm{S}} \quad$ - shrimp mass, kg shrimp

$M_{\mathrm{S}, 0} \quad$ - shrimp mass at initial, $\mathrm{kg}$ shrimp

$M_{\mathrm{S}, \text { max }} \quad$ - shrimp mass at maximum growth, kg shrimp

$M_{\text {Sed, N }} \quad$ - nitrogen in sediment per unit volume of pond water, $\mathrm{kg} \mathrm{N} \mathrm{m}^{-3}$

$P \quad$ - delay in $T_{\max }$ with respect to $L S H, \mathrm{~h}$

$q_{\mathrm{F}} \quad-$ feed rate per shrimp mass, $\mathrm{kg}$ feed $\mathrm{kg}^{-1}$ shrimp $\mathrm{h}^{-1}$

$q_{\text {TAN }} \quad-$ TAN fraction of shrimp respiration to total nitrogen metabolite, -

$R \quad-$ gas constant, $\mathrm{J} \mathrm{mol}^{-1} \mathrm{~K}^{-1}$

$r_{\mathrm{F}} \quad-$ feed rate per unit area of shrimp pond, $\mathrm{kg}$ feed $\mathrm{h}^{-1}$

$r_{\text {mbb,N }}-$ nitrogen metabolite excretion rate by shrimp, $\mathrm{kg} \mathrm{N} \mathrm{m}{ }^{-3} \mathrm{~h}^{-1}$

$r_{\mathrm{r}} \quad-$ rate constant of sediment decomposition, $\mathrm{h}^{-1}$

$R_{\mathrm{S}} \quad$ - fraction of shrimp assimilation in feed, -

$R_{\text {Sed }} \quad-$ fraction of leftover in feed, -

$r_{\text {Sed,TAN }}-$ TAN generation rate from sediment $\mathrm{kg} \mathrm{N} \mathrm{m}{ }^{-3} \mathrm{~h}^{-1}$

$r_{\text {ShrTAN }}-$ excretion rate of TAN by shrimp respiration, $\mathrm{kg} \mathrm{N} \mathrm{m}{ }^{-3} \mathrm{~h}^{-1}$

$r_{\text {total,remove }}-$ total TAN removal rate, $\mathrm{kg} \mathrm{N} \mathrm{m}^{-3} \mathrm{~h}^{-1}$

$r_{\text {total,TAN }}-$ total TAN generation rate, $\mathrm{kg} \mathrm{N} \mathrm{m}^{-3} \mathrm{~h}^{-1}$

$t-$ time, $\mathrm{h}$

$T \quad$ - water temperature, $\mathrm{K}$

$t_{\max } \quad-$ cultivation time, $\mathrm{h}$

$T_{\max }^{t_{\max }} \quad-$ maximum daily water temperature, $\mathrm{K}$

$T_{\min } \quad-$ minimum daily water temperature, $\mathrm{K}$

$t_{\mathrm{s}} \quad-$ sunset time, $\mathrm{h}$

$T_{\mathrm{S}} \quad$ - sunset temperature, $\mathrm{K}$

$\eta \quad-$ night length, $\mathrm{h}$

$\mu \quad-$ specific growth rate constant of seaweed, $\mathrm{h}^{-1}$

$\mu_{\max } \quad-$ maximum specific growth rate of seaweed, $\mathrm{h}^{-1}$

$\pi_{\max }-$ maximum specific uptake rate of TAN, $\mathrm{kg} \mathrm{N} \mathrm{kg}^{-1} \mathrm{DM} \mathrm{h}^{-1}$

$\pi_{\text {TAN }} \quad-$ specific uptake rate of TAN, $\mathrm{kg} \mathrm{N} \mathrm{kg}^{-1} \mathrm{DM} \mathrm{h}^{-1}$

$\rho_{\mathrm{S}} \quad-$ culture density of shrimp, $\mathrm{m}^{-3}$

$\rho_{\mathrm{U}} \quad-$ density of seaweed in culture medium, $\mathrm{kg} \mathrm{DM} \mathrm{m}{ }^{-3}$

$\rho_{\mathrm{U}, 0} \quad-$ density of seaweed in culture medium at initial, $\mathrm{kg} \mathrm{DM} \mathrm{m}^{-3}$

$\rho_{\mathrm{U}, t}-$ density of seaweed in culture medium at $t$, $\mathrm{kg} \mathrm{DM} \mathrm{m}{ }^{-3}$ 


\section{References}

1. Takahashi, Y., Itami, T., Kondo, M., Maeda, M., Fujii, R., Tomonaga, S., Supamattaya, K., Boonyarapalin, S., Fish Pathol. 29 (1994) 121.

doi: http://dx.doi.org/10.3147/jsfp.29.121

2. Wang, J. K., Aquacult. Eng. 9 (1990) 61. doi: http://dx.doi.org/10.1016/0144-8609(90)90011-N

3. Lee, C. S., Sweeney, J. N., Richards, Jr. W. K., Aquacult. Eng. 5 (1986) 147. doi: http://dx.doi.org/10.1016/0144-8609(86)90013-0

4. Ryther, J. H., Goldman, J. C., Gifford, C. E., Huguenin, J. E., Wing, A. S., Clarner, J. P., Williams, L. D., Lapointe, B. E., Aquaculture 5 (1975) 163. doi: http://dx.doi.org/10.1016/0044-8486(75)90096-4

5. Chen, S. Y., Pan, L. Y., Hong, M. J., Lee, A. C., Bot. Stud. 53 (2012) 125.

6. Neori, A., Shpigel, M., Ben-Ezre, D., Aquaculture 186 (2000) 279. doi: http://dx.doi.org/10.1016/S0044-8486(99)00378-6

7. Grommen, R., Van Hauteghem, I., Van Wambeke, M., Verstraete, W., Aquaculture 211 (2002) 115. doi: http://dx.doi.org/10.1016/S0044-8486(01)00883-3

8. Voltolina, D., Gómez-Villa, H., Correa, G., Bioresour. Technol. 96 (2005) 359.

doi: http://dx.doi.org/10.1016/j.biortech.2004.04.004

9. de Godos, I., Vargas, V. A., Blanco, S., González, M. C. G., Soto, R., Garcia-Encina, P. A., Becares, E., Muñoz, R., Bioresour. Technol. 101 (2010) 5150. doi: http://dx.doi.org/10.1016/j.biortech.2010.02.010

10. Neori, A., Ragg, N. L. C., Shpigel, M., Aquac. Eng. 231 (1998) 215. doi: http://dx.doi.org/10.1016/S0144-8609(98)00017-X

11. Samocha, T. M., Fricker, J., Ali, A. M., Shpigel, M., Neori, A., Aquaculture 446 (2015) 263. doi: http://dx.doi.org/10.1016/j.aquaculture.2015.05.008

12. Yousef, S. A. H., Alam, A., Buschmann, A. H., Fitzsimmons, K. M., Reviews in Aquaculture 4 (2012) 21. doi: http://dx.doi.org/10.1111/j.1753-5131.2012.01057.x
13. Huang, C. C., Li, H. S., Chen, C. H., J. Harzard. Mater. 159 (2008) 523

doi: http://dx.doi.org/10.1016/j.jhazmat.2008.02.051

14. Arthur, J. R., Lavilla-Pitago, C. R., Subasinghe, R. P., Use of Chemicals in Asian Aquaculture. Asian Fisheries Development Center, Tigbauan, Ilorilo, Philippines, 2000.

15. Li, Z., Boyd, C. E., Aquaculture 432 (2014) 252. doi: http://dx.doi.org/10.1016/j.aquaculture.2014.05.019

16. Sato, K., Eksangsri, T., Egashira, R., J. Chem. Eng. Jpn. 39 (2006) 247. doi: http://dx.doi.org/10.1252/jcej.39.247

17. Sato, K., Ueno, Y., Egashira, R., J. Chem. Eng. Jpn. 39 (2006) 1128. doi: http://dx.doi.org/10.1252/jcej.39.1128

18. Egashira, R., Sato, K., J. Chem. Eng. Jpn. 39 (2007) 454. doi: http://dx.doi.org/10.1252/jcej.40.454

19. Habaki, H., Tajiri, S., Egashira, R., Sato, K., Eksangsri, T., Chem. Biochem. Eng. Q. 25 (2011) 341.

20. Habaki, H., Tajiri, S., Egashira, R., Sato, K., Eksangsri, T., Chem. Biochem. Eng. Q. 27 (2013) 355.

21. Burford, M. A., Lorenzen, K., Aquaculture 229 (2004) 129. doi: http://dx.doi.org/10.1016/S0044-8486(03)00358-2

22. Lorenzen, K., Aquaculture Research 30 (1999) 932. doi: http://dx.doi.org/10.1046/j.1365-2109.1999.00428.x

23. Gulland, J. A., Fish Stock Assessment: A Manual of Basic Methods. Wiley, Chichester (1983).

24. Ogawa, T., Kozasa, H., Terui, G., J. Ferment. Technol. 50 (1971) 143.

25. Burford, M. A., Williams, K. C., Aquaculture 198 (2001) 79. doi: http://dx.doi.org/10.1016/S0044-8486(00)00589-5

26. Lin, M. E. S., Black Tiger Prawn, Solid Corporation, Manila, Philippines (1988) 210.

27. http://www.tmd.go.th/en/province.php?id=55.

28. Shimada, T., Fujioka, Y., Srithong, C., Aryuthaka, C., Fisheries Science 71 (2005) 1249. doi: http://dx.doi.org/10.1111/j.1444-2906.2005.01090.x 